\title{
Non-specific bronchial hyper-responsiveness in children with allergic rhinitis: Relationship with the atopic status
}

Cuttitta G, Cibella F, La Grutta S, Hopps MR, Bucchieri S, Passalacqua $\mathrm{G}$, Bonsignore $\mathrm{G}$. Non-specific bronchial hyper-responsiveness in children with allergic rhinitis: Relationship with the atopic status. Pediatr Allergy Immunol 2003: 14:458-463. @ 2003 Blackwell Munksgaard

An increased prevalence of bronchial hyper-responsiveness (BHR) has been demonstrated in children from a general population, and in nonasthmatic adults with allergic rhinitis. Thus, also children with allergic rhinitis are expected to be at higher risk of BHR. We evaluated the prevalence of BHR in a sample of non-asthmatic children with allergic rhinitis by means of the methacholine (Mch) bronchial challenge, and by monitorizing the airway patency using the daily peak expiratory flow variability (PEFv). Fifty-one children (ranged 6-15 years of age) with allergic rhinitis, ascertained by skin prick test to inhalant allergens, underwent a 14-day peak expiratory flow monitoring, and a Mch bronchial provocation challenge. Thirty healthy children matched for age, and sex served as control group. Thirty-one children in the rhinitis group $(61 \%)$, and six $(20 \%)$ in the control group were Mch + (Mch provocative dose causing a $20 \%$ fall of forced expiratory volume in $1 \mathrm{~s}$ respect to baseline $<2250 \mu \mathrm{g}$, equivalent to $11.50 \mu \mathrm{mol}$ ). In rhinitic children the PEFv did not significantly differ between Mch + and Mchsubjects, but the total serum immunoglobulin E (IgE) were higher among Mch + . The persistent form of rhinitis was significantly associated to Mch positivity. Non-asthmatic children with allergic rhinitis displayed a high prevalence of BHR. The BHR was significantly associated with persistent rhinitis and with higher total IgE levels. Nevertheless, the spontaneous changes in airway patency, as expressed by PEFv, were within normal limits both in Mch + and Mch- children.

\section{Giuseppina Cuttitta ${ }^{1}$, Fabio Cibella ${ }^{1}$, Stefania La Grutta ${ }^{2}$, Maria R. Hopps ${ }^{3}$, Salvatore Bucchieri' ${ }^{1}$, Giovanni Passalacqua ${ }^{4}$ and Giovanni Bonsignore}

${ }^{1}$ Istituto di Biomedicina e Immunologia Molecolare 'Alberto Monroy' del C.N.R., Palermo, Italy, ${ }^{2}$ Allergy Unit, Children Hospital, ARNAS, Palermo, Italy, ${ }^{3}$ Clinica Pneumologica dell'Università, Palermo, Italy, ${ }^{4}$ Allergy and Respiratory Diseases, Department of Internal Medicine, Genoa University, Italy

Key words: bronchial hyper-responsiveness; rhinitis; children; peak expiratory flow; methacholine

Giuseppina Cuttitta, C.N.R., Istituto di Biomedicina e Immunologia Molecolare, via U. La Malfa, 153, I 90146 Palermo, Italy

Tel.: +390916809137

Fax: +390916809122

E-mail: cuttitta@ifr.pa.cnr.it

Accepted 10 March 2003
Bronchial hyper-responsiveness (BHR) is considered a distinctive functional characteristic of asthma and it is associated with an increased risk for developing bronchial asthma both in children and adults (1). BHR can be detected frequently in subjects suffering from allergic rhinitis alone, thus suggesting that a common pathogenic mechanism operates in the lower airways in allergic rhinitis and asthma. The methacholine (Mch) challenge is the most commonly used and better standardized test for quantifying BHR. Also the spontaneous changes in airway patency, measured by assessing the variability of daily peak expiratory flow $(\mathrm{PEFV})$, is a reliable indirect marker of BHR (2). An increased prevalence of BHR has been demonstrated in children in a general population setting (3), as well as in adult allergic subjects with rhinitis symptoms and no evidence of asthma, related to lower respiratory tract involvement (4). Moreover, non-asthmatic children with allergic rhinitis are most likely to have BHR (5). Nevertheless, at the present, the clinical significance of asymptomatic BHR remains to be fully understood (6). Many factors (e.g., atopic status, family history, sensitization, age at onset of disease, etc.) have been reported to affect at variable extent the relationships among BHR, rhinitis, and asthma, but a comprehensive evaluation of these factors together in a carefully selected population still lacks.

The aim of the present study was to evaluate the prevalence of BHR in a sample of 
non-asthmatic children with allergic rhinitis, by measuring the Mch reactivity and the daily variability of PEF. A number of concomitant demographic and clinical aspects, and their relationship with BHR were evaluated as well.

\section{Methods}

Study design

The present study is a cross-sectional evaluation of bronchial hyper-responsiveness in a group of 51 children with allergic rhinitis alone and in a matched control group of 30 healthy non-allergic children. All subjects were investigated for their clinical history and underwent a careful diagnostic evaluation including: skin prick test (SPT), total serum immunoglobulin E (IgE) measurement, pulmonary function testing, and Mch bronchial challenge. All parents of the subjects signed a written informed consent. The study was approved by the inner Ethical Committee. According to the Italian law, the respect of individual privacy concerning clinical data was granted.

\section{Subjects and diagnosis}

The two groups of children were selected from consecutive outpatients attending the allergy unit of a teaching hospital for the first time. The rhinitis group consisted of patients fulfilling the following criteria:

(i) clinical diagnosis of rhinitis (7) based on the clinical history of nasal blockage, sneezing, itching, and discharge not because of common cold;

(ii) positive SPT for one or more inhalatory allergens;

(iii) no ongoing pharmacologic treatment for rhinitis on a regular basis or specific immunotherapy.

The subjects of the control group were seen as well at the allergy unit, but for non-respiratory symptoms (e.g., urticaria, drug intolerance): they had negative SPT and negative clinical history for rhinitis. None of the children of both groups had a history of asthma symptoms, including diurnal or nocturnal wheezing, recurrent dry cough, shortness of breath, chest tightness or exerciserelated respiratory symptoms. All of them were free from upper or lower respiratory tract infections in the 30 days preceding the study. The treatment prescription, if any, for rhinitis was postponed to the end of the study (14 days).
In the group of children with allergic rhinitis, age of disease onset, disease duration, passive smoke exposure, and family history were assessed in detail. The familial atopic risk was evaluated according to the criteria of Croner and Kjellman (8). Allergic rhinitis was classified as persistent (symptoms at least 4 days per week and more than 4 weeks per year) or intermittent (symptoms $<4$ days per week or $<4$ weeks per year), according to the recent guidelines (9).

Skin prick test was carried out with a standard panel of commercial extracts (Lofarma S.p.A, Milan, Italy). The panel included: Dermatophagoides pteronyssinus, grass pollen, Parietaria judaica, Phleum pratense, artemisia, olive, dog and cat dander, alternaria, and Cladosporium plus a positive (histamine $1 \%$ ) and a negative (isotonic saline) control. The response was measured after $15 \mathrm{~min}$ as the mean value of the major diameter of the wheal and its orthogonal; a reaction of $5 \mathrm{~mm}$ or greater was considered positive (10). Total serum IgE were determined in all subjects by latex nephelometry (Behring Institute, L'Aquila, Italy), log-transformed and expressed as Z-scores (11) according to age groups 6-10 and 11-16 years. All the positive SPTs were confirmed by measuring specific IgE using the FEIA-CAP System (Pharmacia, Upssala, Sweden) (12). Specific IgE were considered positive if their concentration was $0.36 \mathrm{kU} / 1$ (CAP class I). A peripheral eosinophil count was also performed in allergic children.

\section{Peak expiratory flow monitoring}

All rhinitis subjects were instructed to use twice daily (after awakening and at bedtime) a portable peak expiratory flow rate meter (Mini Wright Peak Flow Meter, Clement Clarke Ltd, London, UK), performing forced expiratory maneuvers in standing position starting from vital capacity and selecting the best of three consecutive measurements. All subjects recorded on a diary card PEF measurements and any respiratory symptom occurring over the 14 consecutive day period before $\mathrm{Mch}$ challenge. PEFv was computed as 14-day mean of the daily differences between the highest and lowest values expressed as percent of the daily mean, according to the formula (13):

$$
\operatorname{PEFv}=\frac{1}{14} \times \sum_{1}^{14} \frac{\operatorname{Max}-\operatorname{Min}}{\bar{X}}
$$

where Max, Min and $\bar{X}$ are the daily maximum, minimum, and mean values, respectively. 


\section{Cuttitta et al.}

Pulmonary function tests and methacholine challenge

Pulmonary function tests (PFT) were performed in all subjects by a computerized water-sealed spirometer (Biomedin, Padua, Italy). Baseline forced vital capacity (FVC), forced expiratory volume in $1 \mathrm{~s}\left(\mathrm{FEV}_{1}\right)$, and $\mathrm{FEV}_{1} / \mathrm{FVC}$ ratio, were measured. Mch bronchial provocation test was performed using an ampoule-dosimeter (Mefar Elettromedicali, Brescia, Italy). An inspiratory effort for $0.5 \mathrm{~s}$ activated a solenoid valve, delivering $5 \mu \mathrm{l}$ of solution. Lyophilized Mch chloride (Lofarma S.p.A) was reconstituted, to obtain $0.2 \%$ and $1.0 \%$ concentrations. After saline control, Mch was administered in double increasing amounts: each subject inhaled one and two breaths of $0.2 \%$ Mch solution (each breath corresponding to $10 \mu \mathrm{g}$ of $\mathrm{Mch}$ ), followed by 1,2 , $4,8,16$, and again 16 breaths of $1.0 \%$ solution (each corresponding to $50 \mu \mathrm{g}$ of Mch). $\mathrm{FEV}_{1}$ was recorded about 2 min after each Mch dose (14). All bronchial challenges were performed at the same hour of the day under the same environmental conditions. The Mch test was carried out of the pollen season in those patients with pollinosis. The cumulative administered dose of Mch causing a reduction of $20 \%$ of the baseline $\mathrm{FEV}_{1}\left(\mathrm{PD}_{20}\right)$ was computed by interpolating the Mch cumulative doses immediately preceding and following the $20 \%$ fall of $\mathrm{FEV}_{1}$. Subjects showing a $\mathrm{PD}_{20}<2250 \mu \mathrm{g}$ Mch (equivalent to $11.50 \mu \mathrm{mol} \mathrm{Mch}$ ) were considered as responders $(\mathrm{Mch}+)$, and the remaining were considered non-responders (Mch-). Dose-response slopes (DRS) were calculated for each subject as the ratio between percent decline in $\mathrm{FEV}_{1}$ (from the post-saline value) over the cumulative dose of Mch (15). Using this procedure we obtained a continuous index of BHR in the non-responders, when a $\mathrm{FEV}_{1}$ fall $>20 \%$ was not obtained.

\section{Data analysis}

As the distribution of DRS and PEFv values was highly skewed, all statistical analyses were performed after natural log transformation (lnDRS and $\ln P E F v$, respectively) (16). The one-way ANOVA was used to test differences between groups and subgroups. The chi-square analysis was performed to evaluate differences in frequency distributions of variables. The Mann-Whitney $U$-test (MWU) was used for the comparison of non-parametric variables. The correlation between different variables was tested by simple and multiple linear regression analysis. A p-value $<0.05$ was considered statistically significant.

\section{Results}

All the selected subjects completed the study. Rhinitis and control groups were matched for sex distribution, age, height, and baseline lung function, as summarized in Table 1. Baseline lung function was within normal limits in both groups (17). The median total serum IgE value in children with allergic rhinitis was significantly higher with respect to the control group $(\mathrm{p}=0.0018, \mathrm{MWU}-$ Table 1$)$.

In the control group, six of $30(20 \%)$ children had a $\mathrm{PD}_{20}$ within the range of $240-1950 \mu \mathrm{g}$ (Mch + subgroup). Among controls, the IgE Z-score was not significantly different between Mch + and Mch- subjects (ANOVA). In the rhinitis group, the Mch + children were 31 of $51(61 \%)$, with a $\mathrm{PD}_{20}$ ranging between 173 and $2010 \mu \mathrm{g}$ (Table 1). The frequency distribution analysis showed a significant higher number of $\mathrm{Mch}+$ subjects in the rhinitis group $\left(\chi^{2}, \mathrm{p}=0.0003\right)$, but the difference in $\mathrm{PD}_{20}$ between the two subgroups of Mch + was not significant (MWU). The median

Table 1. Anthropometric, pulmonary function, and atopy characteristics of the two groups of subjects

\begin{tabular}{|c|c|c|c|}
\hline & Control group $(n=30)$ & Rhinitis group $(n=51)$ & p-Value \\
\hline $\operatorname{Sex}(M / F)$ & $18 \mathrm{M} ; 12 \mathrm{~F}$ & $29 \mathrm{M} ; 22 \mathrm{~F}$ & $\chi^{2}: \mathrm{NS}$ \\
\hline Age (years) & $10.6 \pm 1.9$ & $10.8 \pm 2.5$ & ANOVA: NS \\
\hline Height $(\mathrm{cm})$ & $143.7 \pm 9.7$ & $144.4 \pm 13.6$ & ANOVA NS \\
\hline Baseline FVC (I) & $2.6 \pm 0.47$ & $2.9 \pm 0.79$ & ANOVA NS \\
\hline $\begin{array}{l}\text { Baseline } \mathrm{FEV}_{1} \text { (\% of } \\
\text { predicted) }\end{array}$ & $106.8 \pm 10.5$ & $109.9 \pm 11.5$ & ANOVA: NS \\
\hline Baseline $\mathrm{FEV}_{1} / \mathrm{FVC}$ ratio (absolute \%) & $90.2 \pm 5.8$ & $91.3 \pm 6.7$ & ANOVA: NS \\
\hline Total serum IgE, kU/I (median and range) & $87(54-114)$ & $190(24-1300)$ & MWU: 0.0018 \\
\hline Mch+/Mch- & $6 / 24$ & $31 / 20$ & $\chi^{2}: 0.0003$ \\
\hline $\mathrm{PD}_{20} \mathrm{FEV}_{1}$ ( $\mu \mathrm{g}$ Mch, median and range, for Mch+ subjects only) & $445(240-1950)$ & $695(173-2010)$ & MWU: NS \\
\hline DRS $\left(\% F V_{1}\right.$ fall $/ \mu \mathrm{g}$ Mch, median and range) & $0.0025(0-0.0933)$ & $0.0127(0.0005-0.1275)$ & MWU: 0.0021 \\
\hline
\end{tabular}

ANOVA, one-way analysis of variance; MWU, Mann-Whitney U-test; FVC, forced vital capacity; FEV , forced expiratory volume in $1 \mathrm{~s}$; IgE, immunoglobulin E; DRS, dose-response slopes; NS, not significant.

Data are expressed as mean \pm SD unless otherwise indicated. 
DRS was $0.0127\left(\% \mathrm{FEV}_{1} \times \mu \mathrm{g} \mathrm{Mch}^{-1}\right)$ in rhinitics and 0.0025 in controls. The difference was statistically significant (MWU, $\mathrm{p}=0.0021$ ), as summarized in Table 1.

In the rhinitic children the median total serum IgE was $422 \mathrm{kU} / 1$ (range 25-1300) in $\mathrm{Mch}+$ subgroup, and 173 (24-940) in Mch-subgroup. The IgE Z-score was significantly higher in the $\mathrm{Mch}+$ subgroup (ANOVA, $\mathrm{p}<0.002$ ) as shown in Table 2. Moreover, a significant association between Mch positivity and persistent rhinitis was found $\left(\chi^{2}, p=0.0013-\right.$ Table 3$)$. Conversely, age, sex distribution, atopy score (expressed as number of positive SPT), familial atopic risk, age at onset of disease, disease duration, passive smoke exposure, eosinophil count, and baseline airway function (FVC, $\mathrm{FEV}_{1} \%$ predicted, $\mathrm{FEV}_{1} / \mathrm{FVC} \%$ ) did not differ between Mch + and Mch- subgroups (Table 2).

In the whole sample (rhinitics and controls), significant inverse linear relationships were found between $\operatorname{lnDRS}$ with age $\left(\mathrm{p}=0.0019, \mathrm{R}^{2}=\right.$ 0.115 - Fig. 1), with height $\left(\mathrm{p}=0.028, \mathrm{R}^{2}=\right.$ $0.061)$, and with baseline $\mathrm{FEV}_{1}(\mathrm{p}=0.045$,

Table 2. Clinical and functional characteristics of the children with allergic rhinitis ( $n=51$ ), for Mch+ and Mch- subgroups

\begin{tabular}{|c|c|c|c|}
\hline & $\begin{array}{c}\text { Mch+, } \\
\mathrm{n}=31 \\
(61 \%)\end{array}$ & $\begin{array}{c}\text { Mch-, } \\
\mathrm{n}=20 \\
(39 \%)\end{array}$ & p-Value \\
\hline Age (years) & $10.2 \pm 2.5$ & $11.6 \pm 2.3$ & ANOVA: NS \\
\hline Baseline FVC (I) & $2.80 \pm 0.78$ & $2.95 \pm 0.82$ & ANOVA: NS \\
\hline $\begin{array}{l}\text { Baseline } \mathrm{FEV}_{1} \text { (\% of } \\
\text { predicted) }\end{array}$ & $110.3 \pm 10.5$ & $109.4 \pm 13.2$ & ANOVA: NS \\
\hline $\begin{array}{l}\text { Baseline } \mathrm{FEV}_{1} / \mathrm{FVC} \text { ratio } \\
\text { (absolute \%) }\end{array}$ & $91.4 \pm 7.5$ & $91.3 \pm 5.5$ & ANOVA: NS \\
\hline $\operatorname{lgE} Z$-score & $0.43 \pm 1.12$ & $-0.52 \pm 0.59$ & ANOVA $<0.002$ \\
\hline $\begin{array}{l}\text { PEFv (\%, median } \\
\text { and range) }\end{array}$ & $4.89(1.84-11.6)$ & $4.97(1.75-11.8)$ & MWU: NS \\
\hline $\begin{array}{l}\mathrm{N}^{\circ} \text { of positive skin tests } \\
\text { (median and range) }\end{array}$ & $2(1-6)$ & $3(1-10)$ & MWU: NS \\
\hline $\begin{array}{l}\text { Eosinophil count (cell/ } / \mathrm{mm}^{3} \text {, } \\
\text { median and range) }\end{array}$ & $241(90-816)$ & $238(72-340)$ & MWU: NS \\
\hline
\end{tabular}

ANOVA, one-way analysis of variance; MWU, Mann-Whitney U-test; Mch, methacholine; FVC, forced vital capacity; $\mathrm{FEV}_{1}$, forced expiratory volume in $1 \mathrm{~s}$; $\lg \mathrm{E}$, immunoglobulin $\mathrm{E} ; \mathrm{NS}$, not significant

Data are expressed as mean \pm SD unless otherwise indicated.

Table 3. Contingency table of the distribution of subjects and duration of rhinitis symptoms in methacholine (Mch+) and Mch- subgroups for rhinitic subjects $\left(\chi^{2}, p=0.0013\right)$

\begin{tabular}{lccc}
\hline & Persistent & Intermittent & Total \\
\hline Mch+ & 28 & 3 & 31 \\
Mch- & 10 & 10 & 20 \\
Total & 38 & 13 & 51 \\
\hline
\end{tabular}

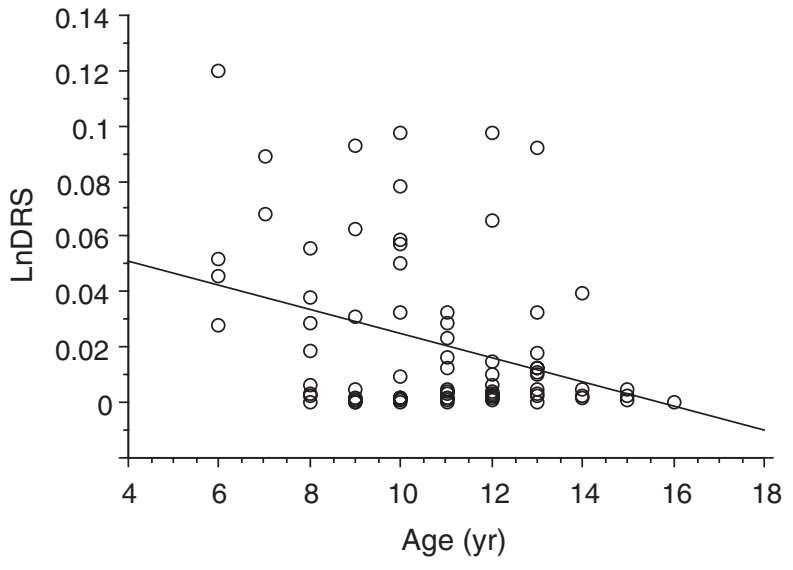

Fig. 1. Linear regression between natural log of methacholine (Mch) dose-response slopes (lnDRS, \% $\mathrm{FEV}_{1} \times$ $\mu \mathrm{g} \mathrm{Mch}^{-1}$ ) and age in the whole sample: $\mathrm{R}^{2}=0.115$, $\mathrm{p}=0.0019$.

Table 4. Simple linear regressions between natural log transformation of dose-response slopes (InDRS) as dependent variable and some independent variables in the whole sample (rhinitics and controls) and the methacholine $(\mathrm{Mch}+)$ subjects only. $\mathrm{R}^{2}$ and $\mathrm{p}$-values are shown

\begin{tabular}{lcc}
\hline Independent variable & Whole sample $\mathrm{R}^{2}(\mathrm{p})$ & $\mathrm{Mch}+\mathrm{R}^{2}(\mathrm{p})$ \\
\hline Age & $0.115(0.0019)$ & $0.130(0.02)$ \\
Height & $0.061(0.028)$ & $0.113(0.04)$ \\
Forced vital capacity & $0.045(0.058)$ & $0.145(0.02)$ \\
Z-score & $0.0001(0.94)$ & $0.188(0.044)$ \\
\hline
\end{tabular}

$\mathrm{R}^{2}=0.050$ ), while the relationship with FVC was close to the significance level ( $\mathrm{p}=0.058$, $\left.\mathrm{R}^{2}=0.045\right)$. These same relationships showed an increase in $\mathrm{R}^{2}$ values when evaluated in Mch + subjects alone (Table 4).

In rhinitis patients, the median PEFv was $4.89 \%$ (range 1.84-11.60) in the Mch + subgroup and $4.97 \%$ (range 1.75-11.80) in the Mchsubgroup, the difference being not significant (Table 2). In the Mch + subgroup, the lnPEFv was inversely related to age $\left(\mathrm{p}=0.013, \mathrm{R}^{2}=\right.$ $0.196)$, to height $\left(\mathrm{p}=0.003, \mathrm{R}^{2}=0.280\right)$, to FVC $\left(p=0.002, R^{2}=0.290\right)$, and to disease duration $\left(\mathrm{p}=0.015, \mathrm{R}^{2}=0.187\right)$. We also found a significant linear relationship between $\ln P E F v$ and the level of BHR expressed as $\operatorname{lnDRS}$ $\left(\mathrm{p}=0.0021, \mathrm{R}^{2}=0.282-\right.$ Fig. 2$)$.

We performed a multiple linear regression analysis between $\operatorname{lnDRS}$ as dependent variable and age, height, FVC, Z-score, and $\operatorname{lnPEFv}$ as independent variables. This analysis produced an increase in $\mathrm{R}^{2}$ value with respect to single linear regressions: $R^{2}$ was $0.529,(p=0.0048)$ in the $\mathrm{Mch}+$ subgroup alone. 


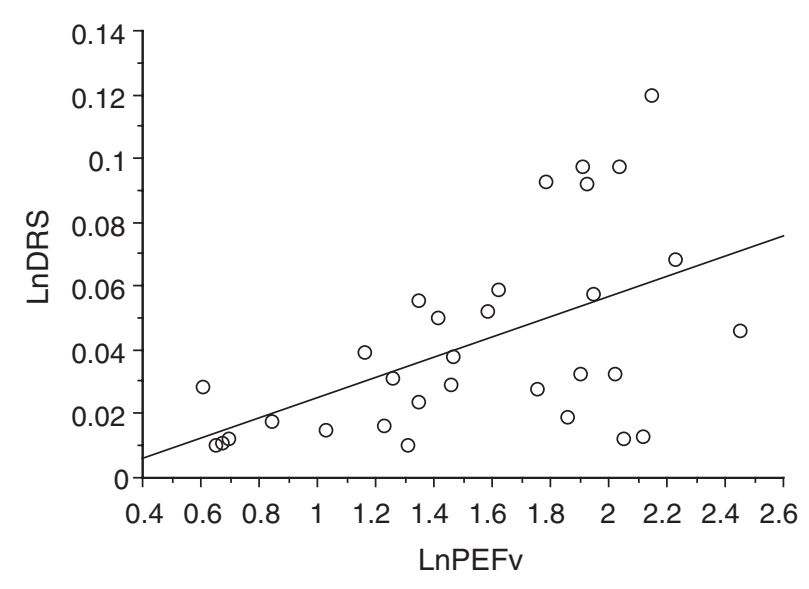

Fig. 2. Linear regression between natural log of mean daily peak expiratory flow (PEF) variability (lnPEFv, \%) and natural log of methacholine (Mch) dose-response slopes $\left(\operatorname{lnDRS}, \% \mathrm{FEV}_{1} \times \mu \mathrm{g} \mathrm{Mch}^{-1}\right)$ in the $\mathrm{Mch}+$ rhinitis subgroup alone: $\mathrm{R}^{2}=0.283, \mathrm{p}=0.0021$.

\section{Discussion}

The present study confirmed that the prevalence of BHR is quite high $(61 \%)$ in non-asthmatic children with allergic rhinitis and about threefold higher than in a control group $(20 \%)$ of matched healthy children. BHR, as measured by Mch test, resulted significantly associated with persistent rhinitis and with higher total serum IgE levels. Conversely, the spontaneous variability of airway patency, evaluated by the daily PEFv, was not different between $\mathrm{Mch}+$ and Mch- children.

We selected a $\mathrm{PD}_{20}$ cut-off value for positive BHR of $2250 \mu \mathrm{g}$ Mch $(11.50 \mu \mathrm{mol})$, value close to the level used in a previous study (18). Despite the large difference in the number of $\mathrm{Mch}+$ subjects between rhinitis and control groups, we found similar $\mathrm{PD}_{20}$ values in all Mch + subjects (Table 1). The prevalence of Mch test positivity in the control group is close to that reported in other studies carried out in asymptomatic children from open populations showing that the BHR prevalence is significantly higher among normal children than among adults (19). Indeed, Koh et al. (5) found a $37 \%$ prevalence of BHR, but this lower prevalence may be explained by both methodologic differences relevant to challenge methods and the selected cut-off value for positive BHR. Moreover, the mean total serum IgE level shown by the population sample in Koh's study was lower. As high total serum IgE level was demonstrated predictive of bronchial reactivity (20), such difference may further account for differences in BHR prevalence. In our study, the total serum IgE level, expressed as
Z-score, was significantly higher in $\mathrm{Mch}+$ subjects as compared with Mch-. Our results further confirm the well known correlation between atopy and BHR (21). All subjects with positive skin tests for seasonal pollens were challenged out of the pollen season. In fact, children with perennial allergic rhinitis, the continuous exposure to an offending allergen could induce a heightened risk of BHR with respect to subjects with seasonal rhinitis (22). In agreement, we found that a higher number of subjects with persistent symptoms was present in the Mch+ subgroup. This suggests that perennial allergen exposure can maintain a persistent inflammation and sustain BHR, thus supporting the hypothesis that inflammation acts as a link between upper and lower airways (23).

We found a significant inverse relationship between BHR (expressed as $\operatorname{lnDRS}$ ), and both age and height, this finding may be attributed to the effect of lung size, as expressed by age and height, on BHR (24). Thus, the lower mean age of population sample in the present study may further explain the higher BHR prevalence we found.

In epidemiological studies, other factors were related to BHR, such as familial atopic risk, passive smoke exposure, number of SPTs, and disease duration. Our study failed in demonstrating these links. This discrepancy may be because of the homogeneity of our patients, entirely represented by children with allergic rhinitis.

Furthermore, we found that in non-asthmatic allergic children the variability of airway patency is superimposable in children with or without BHR: only four subjects (two $\mathrm{Mch}+$ and two Mch-) showed a PEFv higher than 9.26\%, value previously found as 95 th percentile limit for asymptomatic non-asthmatic children (25). In the present study, in rhinitis patients PEFv was significantly linearly related to DRS, even if the relationship was stronger among $\mathrm{Mch}+$ subjects alone and not significant among $\mathrm{Mch}-$. It is noteworthy that despite this relationship, the spontaneous airway reactivity, expressed by PEFv, was not distinguishable among Mch + and Mch- subjects. From a clinical point of view these results suggest that in non-asthmatic children the presence of BHR does not imply an abnormal behavior of airways, as found in asthmatics (2). In rhinitic non-asthmatic children, a positive Mch test is not definitely associated with abnormal spontaneous diurnal changes in airway patency.

In conclusion, in a selected sample of children with allergic rhinitis alone we found a very high prevalence of asymptomatic BHR. This was associated with persistent rhinitis and higher 
total serum IgE levels. Nevertheless, the spontaneous changes in airway patency, as expressed by diurnal variability of peak expiratory flow, were within normal limits both in responder and nonresponder children.

\section{References}

1. Hopp RJ, Townley RG, Biven RE, Bewtra AK, Nair NM. The presence of airway reactivity before the development of asthma. Am Rev Respir Dis 1990: 141: 2-8.

2. Ryan G, Latimer KM, Dolovich J, Hargreave Fe. Bronchial responsiveness to histamine: relationship to diurnal variation of peak flow rate, improvement after bronchodilator, and airway calibre. Thorax 1982: 37: 423-9.

3. Hopp RJ, Bewtra A, Nair NM, Townley RG. The effect of age on methacholine response. J Allergy Clin Immunol 1985: 76: 609-13.

4. Ramsdale EH, Morris MM, Roberts RS, Hargreave FE. Asymptomatic bronchial hyperresponsiveness in rhinitis. J Allergy Clin Immunol 1985: 75: 573-7.

5. KoH YY, LeE MH, KIM CK, et al. A familial predisposition in bronchial hyperresponsiveness among patients with allergic rhinitis. J Allergy Clin Immunol 1998: 702: 921-6.

6. Grembiale RD, Camporota L, Naty S, Tranfa CM, DJuKANOVIC R, Marsico SA. Effects of specific immunotherapy in allergic rhinitic individuals with bronchial hyperresponsiveness. Am J Respir Crit Care Med 2000: 162: 2048-52.

7. The International Rhinitis Management Working Group. International Consensus Report on the Diagnosis and Management of Rhinitis. Allergy 1994: 49 (Suppl 19): 1-34.

8. Croner S, KJellman NI. Development of atopic disease in relation to family history and cord blood $\mathrm{IgE}$ levels: eleven-years follow-up in 1654 children. Pediatr Allergy Immunol 1990: 1: 14-20.

9. Bousquet J, Van Cauwenberge P, Khaltaev N. Aria Workshop Group. World Health Organization. Allergic rhinitis and its impact on asthma. J Allergy Clin Immunol 2001: 108: S147-334.

10. Dreborg S, Frew A. Position paper: allergen standardization and skin tests. Allergy 1993: 48(suppl 14): 57-62.

11. Burrows B, Martinez FD, Halonen M, Barbee RA, Cline MG. Association of asthma with serum IgE levels and to skin-test rectivity to allergens. N Engl J Med 1989: 320: 271-7.

12. Axen R, Drevin H, Kober A, Yman L. A new laboratory diagnostic system applied to allergy testing. N Engl Reg Allergy Proc 1988: 9: 503-8.
13. Higgins BG, Britton JR, Chinn S, et al. The distribution of peak expiratory flow variability in a population sample. Am Rev Respir Dis 1989: 140: 1368-72.

14. Sterk PJ, Fabbri LM, Quanjer PhH, et al. Airway responsiveness. Standardized challenge testing with pharmacological, physical and sensitizing stimuli in adults. Eur Respir J 1993: 6(Suppl 16): 53-83.

15. O'Connor G, Sparrow D, Taylor D, Segal M, Weiss $\mathrm{S}$. Analysis of dose-response curves to methacholine. Am Rev Respir Dis 1987: 36: 1412-7.

16. Paoletti P, Carrozzi L, Viegi G, et al. Distribution of bronchial responsiveness in a general population: effect of sex, age, smoking and level of pulmonary function. Am J Respir Crit Care Med 1995: 151: 1770-7.

17. Polgar G, Promadhat V. Pulmonary function testing in children: techniques and standards. Philadelphia, London, Toronto: WB Saunders Co, 1971.

18. Josephs LK, Gregg I, Mullee MA, Holgate ST. Nonspecific bronchial rectivity and its relationship to the clinical expression of asthma. Am Rev Respir Dis 1989: 140: 350-7.

19. Weiss St, Tager IB, Weiss JW, Munoz A, Speizer Fe, INGRAM RH. Airway responsiveness in a population sample of adults and children. Am Rev Respir Dis 1984: 129: 898-902.

20. Sears Mr, Burrows B, Flannery EM, Herbison GP, Hewitt CJ, Holdaway MD. Relation between airway responsiveness and serum $\mathrm{IgE}$ in children with asthma and in apparently normal children. N Engl J Med 1991: 325: 1067-71.

21. Crockcroft DW, Murdock KY, Berscheid BA. Relationship between atopy and bronchial responsiveness to histamine in a random population. Ann Allergy 1984: 53: 26-9.

22. Verdiani P, Di Carlo S, Baronti A. Different prevalence and degree of nonspecific bronchial hyperreactivity between seasonal and perennial rhinitis. J Allergy Clin Immunol 1990: 86: 576-82.

23. Passalacqua G, Canonica GW. Impact of rhinitis on airway inflammation: biological and therapeutic implications. Respir Res 2001: 2: 320-3.

24. Peat JK, Salome CM, Xuan W. On adjusting measurements of airway responsiveness for lung size and airway caliber. Am J Respir Crit Care Med 1996: 154: $870-5$.

25. Siersted HC, Hansen HS, Hansen N-CG, HyldeBRANDT N, Mostgaard G, Oxhou H. Evaluation of peak expiratory flow variability in an adolescent population sample. Am J Respir Crit Care Med 1994: 149: 598-603. 